\title{
Trajetórias Investigativas da Possessão: Uma Abordagem Etnopsicológica*
}

\author{
Investigative Courses on Spirit Possession: An Ethnopsychological Approach
}

\author{
Rafael de Nuzzi Dias ${ }^{1}$ \\ José Francisco Miguel Henriques Bairrão ${ }^{\mathrm{I}}$
}

\section{Resumo}

Não obstante a sua grande difusão na sociedade nacional, o estudo da possessão tem recebido relativamente pouca atençáo por parte dos psicólogos brasileiros. Neste artigo, com base em uma revisão da principal literatura clássica e contemporânea sobre possessão e na descrição sumária dos resultados de algumas pesquisas, discutem-se vantagens comparativas de uma abordagem etnopsicológica da possessão embasada na psicanálise lacaniana.

Palavras-chave: Etnopsicologia; possessão; psicanálise e cultura; cultos afro-brasileiros.

\section{Abstract}

Despite its large diffusion in the national society, the study of possession has received relatively little attention from Brazilian psychologists. In this article, based on a review of major classic and contemporary literature about possession and on a brief description of some researches' results, comparative advantages of an ethnopsychological approach to possession, grounded in Lacanian psychoanalysis, are discussed.

Keywords: Ethnopsychology; spirit possession; psychoanalysis and culture; afro-brazilian cults.

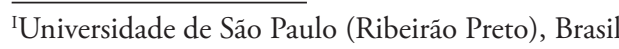

Embora a utilização científica do conceito de "possessão" possa ser objeto de discussão, e mesmo de objeção, e mereça ser investigada a sua genealogia, que mais não seja em virtude do elo que implicitamente estabelece entre a demonologia cristá e práticas de "povos selvagens" (Johnson, 2011), é fato que, independentemente dos termos adotados e da sua diversidade, há, na maioria das culturas, dispositivos culturais que permitem a outras vozes falarem por meio dos corpos humanos e há indícios de que elas falam mais vezes e mais alto em contextos de dissidência contra situaçóes de opressão e de subordinação de uma cultura por outra (Hegeman, 2013).

O transe de possessão, a comunicação direta com o sagrado através da incorporação de espíritos por pessoas dispostas e preparadas para a função, é um fenômeno complexo existente em todo o mundo e elemento central na maioria dos sistemas religiosos (Bourguignon, 1973) que há muito intriga os pesqui- sadores, tendo se tornado um importante campo de estudo das ciências humanas e sociais.

Contudo, não obstante enquanto forma particular de contato com o sobrenatural seja uma referência constante na religiosidade brasileira,

um fenômeno que é bastante familiar a todos na nossa cultura, mas que nem por isso deixa de despertar sentimentos contraditórios de medo e fascínio (Birman, 1985, p. 8-9),

até o momento os estudos sobre a possessão calcados em abordagens por assim dizer transdisciplinares - sensíveis não apenas aos seus aspectos simbólico-culturais e sociológicos, mas também aos subjetivos e psicológicos - restringiram-se em grande medida a autores estrangeiros. Tal fato náo é casual, sendo corolário, por um lado, do ainda restrito número de 
cientistas sociais brasileiros empenhados em investigar a possessão levando em consideração suas dimensões propriamente psicológicas, e por outro, consequência do relativo desinteresse da Psicologia brasileira em relação às religióes de forma em geral e aos cultos de possessão em particular.

$\mathrm{O}$ presente artigo tem por objetivo proceder, com base em uma revisão da literatura científica clássica e mais recente sobre possessão e apoio em uma exposição sumária de alguns resultados de pesquisa, a uma apresentação das contribuiçóes e utilidade de uma abordagem etnopsicológica viabilizada por aportes teórico-metodológicos oferecidos pela psicanálise em sua vertente lacaniana, no intuito de mostrar como esta possibilita enfrentar o estudo dessa temática ultrapassando dificuldades e aprofundando soluções das abordagens anteriores.

\section{Os Primórdios dos Estudos sobre a Possessáo e o Problema dos Reducionismos}

Em trabalho clássico, Concone (1987) apresenta algumas das principais concepçôes científicas propostas sobre a possessão, chamando a atenção para como as discussóes giraram, ao longo de décadas, em torno da temática da normalidade, sendo a possessão muitas vezes caracterizada como patologia mental ou, inversamente, como uma espécie de terapia catártica coletiva. Nesse contexto, um dos aspectos mais enfatizados é a consideração do transe de possessão como um estado transitório e reversível de alteração da consciência, caracterizado por processos dissociativos e descontinuidades das funçôes da personalidade e dos padrôes comportamentais normais.

A subordinação do estudo da possessão ao campo da saúde mental, seja para tentar escrutiná-la psiquiatricamente (Onchev, 2001), seja para ensaiar explicá-la pela psicanálise (Hollan, 2000), seja para simplesmente debater se e em que medida pode ser entendida como um fenômeno normal ou patológico (Cardeña, Van Duijl, Weiner \& Terhune, 2009), seja para propô-la como um dispositivo terapêutico (Bojuwoye, 2013), embora tenha sabido reformular-se e sofisticar-se ao longo do tempo (Swartz, 2011), é recorrente e ainda atual. Seria possível alongar-se a este respeito, mas por não ser esse o objetivo do presente artigo, a cunho ilustrativo, apenas nos deteremos em alguns dos trabalhos mais recentes e representativos deste viés.

A propósito do culto zar, que desde o trabalho pioneiro de Leiris (1958/1996) talvez seja o principal campo de pesquisa e de reflexão acadêmica sobre possessão, o etnopsiquiatra Tobie Nathan, já em pleno século XXI, afirma sem reserva que o djinn (palavra árabe de que se originou o português "gênio"), central no zar, pode ser entendido como um "conceito" suscetível de implicaçôes populares e clínicas e que o seu "tratamento" requer um enfoque que combine psicopatologia com Sociologia e Antropologia (Nathan, 2005). Deste modo ostensivamente ignora ou menospreza a volumosa literatura que vê no culto zar muito mais do que patologias e terapias e que tem sublinhado prestar-se à expressão dos mais diversos temas culturais, dentre os quais constructos etnopsicológicos de selfe de mundo, concepçôes de bem e de mal e assimetrias de poder entre os sexos (Nelson, 1971); compreensão que pode se alargar ao entendimento da possessão neste caso (e em outros similares) como um meio de produzir sentidos a respeito das circunstâncias cambiantes da vida cotidiana e um metacomentário dramatizado a respeito de acontecimentos locais atuais (Kenyon, 1995), muitas vezes em termos satíricos que possibilitam uma espécie de crítica velada e de reflexão sobre a condição de mulher (Boddy, 1989). Mas Nathan não está sozinho, como o comprovam estudos igualmente recentes sobre uma jovem italotunisina tratada por uma combinação de psiquiatria transcultural com fluoxetina (Bragazzi \& Del Puente, 2012) e o estudo de caso de um menino egípcio-canadense (Guzder, 2007).

Assiste total razão a Lambek (1988) quando afirma que a possessão deve ser vista precipuamente como uma instituição social e apenas secundariamente como aflição ou terapia e, dado o reducionismo e o preconceito inerentes àquelas abordagens, historicamente a ênfase tem se deslocado para sua dimensão sociológica e cultural, sendo o transe de possessão entendido como crença que

tecnicamente só pode ser vinculada a um contexto cultural, isto é, a um conjunto de fórmulas explicativas, de caráter místico (Concone, 1987, p. 99).

Transferido o eixo do problema, modificou-se também seu campo disciplinar de referência, que migrou da Medicina para as Ciências Sociais. Consequentemente, sob várias abordagens que acompanharam a trilha das grandes escolas que emergiram nas Ciências Sociais ao longo do século passado, o transe de possessão foi perscrutado em termos da satisfação pessoal que provoca e das funçóes terapêuti- 
cas que desempenha (Boddy, 1988), como expressão e reflexão individual (Masquelier, 2002) ou coletiva de memórias ou acontecimentos atuais aflitivos (Bairrão, 2004), como meio de resistência velada à subordinação a estruturas de gênero (Brac de la Perrière, 2007), como uma afirmação de exclusividade sobre o atinente ao saber nativo (Van De Port, 2005), ora porta-voz do socialmente desviante ora como mecanismo ativo mantenedor do status quo (Lewis, 1977), ou ainda como drama e performance cultural, fenômeno espetacular legitimado segundo linhas de força articuladas no interior do sistema religioso (Turner, 1988), apenas para mencionar algumas abordagens.

Em estudo sobre a possessão no candomblé angola, Goldman (1984), empenhado em uma abordagem estruturalista e antirreducionista que desse conta da estrutura lógica subjacente ao fenômeno e repousaria "em última instância sobre mecanismos básicos do pensamento" (p. 158-159), endossa a tese de que historicamente se sobressaíram fundamentalmente dois modelos teóricos básicos para a explicação do êxtase religioso

que possuem em comum um caráter essencialmente reducionista: seja reduzindo o transe a uma esfera "bio-psicológica", encarando-a ora como doença mental propriamente dita, ora como forma de tratamento "primitivo" para esse tipo de perturbação (ou ainda, no máximo, considerando-o como emergência direta de fenômenos psíquicos "normais"), seja transpondo esse reducionismo para um plano interno à sociedade e vendo na possessáo, e no culto que a encerra, o puro reflexo de estruturas sociopolíticas abrangentes tidas como mais substantivas e determinantes (Goldman, 1984, p. 193).

Consequentemente, Goldman (1984) alerta que o enfrentamento teórico-metodológico do etnocentrismo e do reducionismo deve ser pressuposto na formulação de propostas para a investigação da possessão. "Isso não obstante ele mesmo, ao propor uma abordagem "verdadeiramente antropológica" voltada ao desnudamento de suas estruturas discerníveis simbolicamente, não a reconhecer enquanto veículo portador de subjetividades expressas em nível sensível e estético. De modo que, apesar da contribuição que empreende ao deslocar a tradição dos estudos sobre os cultos de possessão do âmbito dos modelos reducionistas calcados na "traduçáo" do fenômeno em termos palatáveis a constructos teóricos extrínsecos e previamente estabelecidos, Goldman desconsidera que é preciso transitar por intensidades sensíveis, por vezes impensáveis e indizíveis, com vistas a apreender e conhecer o fenômeno humano em sua totalidade (Favret-Saada, 2005).

$\mathrm{Na}$ realidade, um amplo movimento de revisão e ruptura no campo dos estudos acerca da possessão, a partir da tomada de consciência dos problemas do etnocentrismo e do reducionismo, já estava em curso. Concone (1987) exemplifica essa tendência ao afirmar que

o comportamento religioso específico (no caso, o transe de possessão) só pode ser convenientemente avaliado no quadro das regras do comportamento religioso, das normas de comunicação. Os atos específicos só podem ser compreendidos dentro desse universo de normas e as açôes só fazem sentido quando referidas a um universo semântico (p. 111-112, grifos nossos).

Além da ênfase na necessidade de se levar em conta o quadro de referência cultural intrínseco ao fenômeno, compreendendo-o em seus próprios termos, ou seja, na linguagem daqueles que o vivenciam, esse trecho apresenta outra perspectiva norteadora dos estudos contemporâneos acerca do transe de possessão: sua dimensão comunicativa.

\section{A Possessáo como Fenômeno Comunicativo e Reflexivo}

Apesar das diferenças encontradas no transe de possessão em diferentes culturas, os modelos contemporâneos parecem convergir no reconhecimento da centralidade de suas dimensóes comunicativa e reflexiva e tentam fornecer respostas às importantes questôes imediatamente suscitadas: quem comunica (exerce agência)? O que se comunica e elabora? Como a comunicação se manifesta e sob que condiçóes engendra reflexão? Em que termos a comunicaçáo reflexiva fornece escopo a um modelo teórico que abranja o fenômeno em seus mais variados níveis (psíquico, social, histórico, simbólico, cultural, estético, ritual, performático e corporal)? 
Os espíritos podem assumir novas conotaçóes em função de mudanças culturais (Ambros, 2010). A este propósito, cumpre dizer que muitas vezes a possessão foi discutida em termos lato sensu parapsicológicos, como se houvesse de se admitir ou refutar nos seus episódios a interveniência real de coisas tais como espíritos "sobrenaturais". Na realidade, esse enfoque não parece autorizar-se do ponto de vista do que se infere das suas manifestaçôes (Bairrão, 2008b), que em diferentes graus podem reconhecer-se claramente como em si mesmas uma espécie de ficção ou teatro alusivo a espíritos (Snodgrass, 2002), sem que com isso, de modo algum, se desautorize a verdade da experiência e as suas implicaçôes subjetivas.

Crapanzano (1977) entende a possessão como um idioma cultural coletivamente compartilhado, capaz de fornecer aos indivíduos e grupos que dele se utilizam a capacidade de articular, comunicar e elaborar as mais variadas experiências e situaçóes da vida cotidiana. Entretanto, salienta que os sentidos que se consubstanciam no idioma da possessão são articulados de modo eminentemente relacional, por meio de relaçóes continuamente estabelecidas no interior de enquadres sociais definidos que implicam não apenas uma estrutura simbólica calcada em padróes lógicos de referência embora essa gramática seja da maior relevância - mas também uma irredutível dimensão dialógica. Dessa forma, para se compreender a possessão, seria imprescindível estar atento não apenas aos espíritos, mas também às relaçôes dialogicamente estabelecidas entre eles, os médiuns que os recebem e a comunidade que os acolhe e cultua por meio de uma abordagem capaz de abarcar o fenômeno tanto em suas dimensôes lexical e sintática, quanto em sua dimensáo relacional subjetivamente referida; e perscrutar a mediação que se opera entre os níveis pessoal, coletivo e histórico, simbolizando experiências complexas e fornecendo aos agentes do culto pontos de orientação biográfica coletivamente compartilhados.

Na mesma linha, Lambek (1980) sublinha a existência de uma dimensáo subjetiva inerente e concomitante aos aspectos simbólicos da possessão, concebendo-a como um sistema simbólico-comunicativo capaz de veicular mensagens em vários níveis e mediar as esferas pessoal e coletiva da experiência através do estabelecimento de negociaçóes entre a multiplicidade de posiçôes e papéis que interpelam o sujeito membro de uma sociedade e participante de uma cultura. Entretanto, tais mensagens seriam apenas discerníveis por aqueles familiarizados com as propriedades específicas que imprimem or- ganicidade lógica ao sistema e inseridos nos contextos pragmáticos em que se expressam (cerimoniais e litúrgicos, mas também cotidianos e ordinários).

Obeyesekere (1981) é outro autor preocupado com a dimensáo subjetiva envolvida nas produçóes de sentidos que se efetuam em meio a processos simbólico-culturais. Partindo da crítica aos cientistas sociais que negam a existência de uma dimensão psicológica inerente aos símbolos culturais e utilizando-se de um enfoque psicanalítico, o autor defende que os símbolos operam simultaneamente em nível pessoal e cultural, ambos mutuamente imbricados na conformação da experiência religiosa. A possessão permite ao indivíduo apropriar-se de símbolos que consubstanciam a produção de sentidos de realidade compartilhados (em lugar de fantasias ou delírios individuais) e propiciam integração social, criando laços de pertencimento e solidariedade, e psíquica, fornecendo dispositivos simbólicos que estabelecem elos entre as exigências motivacionais do sujeito e os imperativos organizacionais da sociedade.

Stoller (1995) desenvolve uma abordagem da possessão que leva em consideração sua dimensão estética e sensível, corporalmente inscrita, ou seja, que inclua os sentimentos, sensaçôes, intuiçôes e percepções vividas nos seus mais variados níveis. Concebendo o corpo e suas propriedades sensoriais e perceptivas como um verdadeiro lócus de saber capaz de armazenar e refletir memórias coletivas cognoscentes, Stoller discute como, ao inscreverem-se no corpo vivo e conceberem-se como uma espécie de poética comovente e arrebatadora, os espíritos evocam o passado em revivências que reelaboram o presente e permitem sínteses compreensivas e construtivas entre as pessoas e os seus lugares no mundo e na história. Além disso, salienta a importância de serem levadas em conta não apenas as experiências dos nativos, mas também as do pesquisador, o que requer uma percepção mais ampla e aguda que envolva e conceda dignidade epistêmica ao corpo, suas sensaçóes e afetos.

Mageo (1996) apresenta os cultos de possessão como sistemas comunicativos veiculadores de discursos morais, históricos e geográficos constitutivos da memória coletiva de um povo, entremeados a significados e experiências subjetivas atinentes ao indivíduo possuído. Partindo de uma perspectiva que reconhece e integra os níveis individual (psíquico) e coletivo (sócio-histórico-cultural) do fenômeno, afirma que muitas das tensóes e contradiçôes vivenciadas pelos possuídos e mobilizadoras de suas "crises" encontram sua fundamentaçáo em conflitos coletivos calcados em paradoxos morais histórica e culturalmente cons- 
truídos; daí a possibilidade de serem expressos e refletidos através da manipulação dos símbolos mobilizados pela possessão.

Corin (1998) discute como o diálogo com os espíritos permite negociaçóes capazes de rearticular estruturalmente a posição do sujeito em relação aos conflitos que o perturbam. Tomados como alteridades cognoscentes e familiares, eles apresentam uma possibilidade de interlocução e subjetivação de tensões vivenciadas imaginariamente como um embate entre "si mesmo" e "outros poderes" subjugantes e opressivos. Consequentemente, emoçóes inconfessas, desejos insuspeitos e imperativos socioculturais são simbolicamente remodelados, ressignificados e subjetivados, adquirindo novo estatuto e dignidade à medida que os espíritos fornecem operadores simbólicos que viabilizam o estabelecimento de novas identificações, capazes de remodelar a maneira como o indivíduo experiencia a si mesmo e se situa em meio à sociedade onde está inserido, evadindo-se de uma posição de vítima impotente e tornando-se agente frente aos dramas e acontecimentos da sua vida.

Kramer (1993) sublinha o estatuto essencialmente epistêmico e ontológico do fenômeno, instrumento de transmissão, armazenamento e reelaboração de saberes constitutivos da realidade dos povos que dele se beneficiam. Interessado na temática da arte, o autor argumenta que os chamados "objetos de arte africanos" não se constituem enquanto tal no contexto das culturas em que foram forjados, manifestando na realidade uma forma cultural de produção de conhecimento sobre o "outro", seja ele o estrangeiro, o socialmente desviante, a natureza (antítese da civilização), ou "outros internos" (emoções, sensaçôes, impulsos). Paralelamente, afirma que o mesmo se aplica aos cultos de possessão, uma vez que o encontro com o sagrado é via de acesso a relaçôes de alteridade indispensáveis à produção de sentidos capazes de darem forma e consistência ao fragmentado mundo da experiência. Assim, aspectos contraditórios da experiência, individual ou coletiva, podem ser integrados e rearticulados simbolicamente na possessão por meio da comunicação e da identificação com poderes "outros" presentificados em espíritos dotados de força, desejos e intenções.

Augras (2008) sustenta o potencial da possessão para a conformação de processos dinâmicos de transformação pessoal (metamorfoses identitárias) por meio da experiência de duplos articulados no interior de redes de relaçóes sociais (comunitárias e rituais) e simbólicas (míticas). Ademais, destaca que tais efeitos são possíveis pela existência de um sistema simbólico compartilhado, salientando ainda a importância de aspectos não verbais na veiculação de mensagens carregadas de forte teor emocional.

\section{Uma Abordagem Etnopsicológica da Possessáo Umbandista}

Segundo Levine (2005),

Etnopsicologia é uma abordagem descritiva da experiência humana que levanta questôes teóricas difíceis tanto para a psicologia como para a antropologia. Ao descrever as categorias psicológicas nativas de uma cultura em particular, levanta a questão de saber se os conceitos psicológicos ocidentais são apropriados ou necessários para entender pessoas em contextos náo-ocidentais, e se a psicologia como a conhecemos é apenas uma dentre muitas conceptualizações possíveis em vez de uma teoria científica de validade universal. Concomitantemente, uma consideração etnopsicológica póe em questáo se a experiência, individual e coletiva, pode ser adequadamente compreendida exclusivamente em termos de categorias culturais nativas ou se, para uma explicação satisfatória, requer a assunção de processos mentais universais (p. 475-476, tradução nossa).

Ainda conforme Levine,

a etnopsicologia foi independentemente inventada muitas vezes por pesquisadores de campo que encontraram gente de outras culturas usando termos vernáculos para descrever e explicar o que poderíamos chamar de seus processos mentais e experiências subjetivas (2005, p. 476),

de modo que um passo a ser dado pelos estudiosos da área seria a conduçáo de investigaçóes por pesquisadores que orientassem a sua atenção para as suas próprias culturas de origem, em vez do modelo tradicional de ocidentais que procedem a longas e exaustivas imersóes em outras culturas. Exemplifica-o mencionando os estudos 
de Doi (1973) sobre relacionamentos interpessoais no Japão e de Obeyesekere (1981) sobre possessão no Sri Lanka. Algo dessa ordem tem vindo a desenvolver-se no Brasil com base em cultos de possessáo afro-brasileiros como a umbanda.

A possessão umbandista caracteriza-se pela abertura ao atípico e ao inesperado, sendo sua prática raramente atrelada a um controle rígido, o que permite a conformaçáo de espíritos singulares que podem variar de um terreiro ou de um médium para outro, dependendo de suas idiossincrasias e de seus aspectos biográficos, genealogias familiares, valores e aspiraçóes (Rotta \& Bairrão, 2012). Nesse contexto, memórias coletivas e cenários histórico-geográficos também podem alçar-se a significantes e diretrizes para a ação (Macedo \& Bairrão, 2011). Essas possibilidades, entretanto, estão longe de serem caóticas ou arbitrárias, encontrando limites estabelecidos por certos tipos de personagens, como caboclos, pretos-velhos, baianos, boiadeiros, ciganos, pomba-giras, exus, dentre outros menos recorrentes (Concone, 2001).

Em geral articulados a partir de figuras populares que simbolizam e rememoram episódios dramáticos da história nacional, esses personagens ou categorias espirituais são em seu conjunto o eixo central dos ritos e mitos umbandistas, cada qual com características tipológicas específicas bem demarcadas e relativamente persistentes e uniformes. Na prática, tais espíritos apresentam-se como agentes que se expressam estética, corporal e verbalmente (Pagliuso \& Bairrão, 2010) e configuram a dimensão propriamente enunciativa da umbanda (Bairrão, 2005), lugares simbólicos que organizam sentidos no interior do sistema religioso.

Tal qual o sistema de iluminação de um palco, composto de luzes estrategicamente posicionadas opostas, oblíquas, ou adjacentes entre si -, a umbanda é composta por perspectivas (Bairrão, 2002) que delimitam e circunscrevem a maneira específica por meio da qual são abordados ou "iluminados" os conteúdos postos em seu "palco" enunciativo. Essas perspectivas são correlativas às categorias do panteão e seus subtipos, personagens-símbolos que funcionam ao mesmo tempo como

imagens que convidam a olhar e outros olhares que iluminam circunscriçôes próximas do mesmo contexto imaginal e podem narrá-lo (e narrar-se) ao incorporarem-se em interpretaçóes dos seus pontos de vista (Bairrão, 2003a, p. 289).

Quando interpeladas, tais perspectivas podem "lançar luz" a certos aspectos de um conteúdo factual ou ideacional, sendo, entretanto, incapazes de "iluminar" outros, assim como determinada luz em um palco é incapaz de iluminar a face oculta de um objeto focado. Comparando-se os efeitos de "iluminação" produzidos desde diferentes perspectivas, pode-se verificar que são complementares, compõem uma organicidade lógica, estabelecem relaçôes e discriminam aquilo que só pode ser "visto" ou apreendido quando contemplado de uma determinada "posiçâo".

Ademais, essas perspectivas enunciativas comportam uma dimensão dupla. Por um lado, referem posiçóes subjetivas - lugares desde onde se pode atuar como sujeito - articuladas em torno de símbolos extraídos da matéria-prima disponível na cultura - compreendida aqui nos termos do Outro lacaniano, como funçáo de alteridade identificada ao funcionamento da linguagem (em sentido amplo), conjunto de significantes submetidos a determinadas regras de encadeamento.

Por outro lado, abrangem também o espectro de sentidos passíveis de serem imaginariamente produzidos desde determinadas posiçôes, espécie de potencial semântico que define os usos pragmáticos que podem ser empreendidos na elaboração de conflitos e situaçôes cotidianas. Como alguns sentidos somente podem ser enunciados pela via de determinados elementos do código, ou seja, não podem prescindir de uma ancoragem significante específica, ocorre que a cada posição corresponde um potencial semântico circunscrito aos tipos de relaçóes de significância que podem surgir em meio às associaçôes significantes estabelecidas pelos adeptos no afã de obterem uma mediação significativa de suas vivências de realidade.

Nesse sentido, as entidades espirituais devem ser também pensadas em função de como os traços simbólicos que as compóem "acontecem e se ajustam à singularidade de cada médium” (Bairrão, 2003a, p. 286), ou seja, dos usos psicológicos que cada médium faz de seu "panteão pessoal". Pensar as idiossincrasias das entidades que incorporam em determinado médium não é o mesmo que abordá-las enquanto produtos sócio-históricos, de modo que se pode falar delas tanto num contexto subjetivo e singular intrínseco à dupla médium/entidade, quanto num contexto cultural simbolicamente articulado (Rotta \& Bairrão, 2010). 
O reconhecimento desses dois níveis, imbricados, desde onde se pode perscrutar o fenômeno, um simbólico-cultural e outro subjetivo-pragmático, parece o ponto de partida para a reflexão de como uma aproximaçáo pela via da psicanálise na sua vertente lacaniana torna possível entender a possessão umbandista

não meramente como um tipo de ritual capaz de pôr em cena um vasto repertório de símbolos... mas como sendo intrinsecamente um dizer, um processo enunciativo (Bairrão, 2007, p. 165),

canal polissêmico veiculador de mensagens em diversos níveis e sistema idiomático composto por significantes passíveis de serem apropriados e remodelados para a conformação de sentidos subjetivados apenas discerníveis no âmbito das trajetórias individuais de seus interlocutores.

Além de fenômeno cultural em sentido estrito - repertório de símbolos e imagens que resguarda tradiçôes, valores e memórias de parte significativa dos brasileiros —, a cosmologia umbandista apresenta-se simultaneamente como matéria-prima significativa e significante, disponível à reflexão de experiências individuais e coletivas (Bairrão, 2003b), transmutando representaçóes étnicas ancestrais em traços de identificação e marcas de pertencimento com as quais é possível situar-se no mundo contemporâneo (Bairrão, 2011a). Tal processo se dá na relação que cada umbandista estabelece com os espíritos que incorpora ou com os quais se identifica, pois é no espaço dialógico estabelecido diacronicamente com o sagrado enunciante que são promovidas as transformaçóes identitárias que permitem ao sujeito vislumbrar novas maneiras de entender e se inscrever no mundo. Conforme atesta Bairrão (2007):

É crucial entender a leitura do psicológico no espiritual tão-somente como espelhamento do sujeito por um sagrado intrinsecamente especular. Frequentemente é em transe, com base na reflexão dos espíritos, que o sujeito se interpela e se pune, absolve ou admoesta. As personificaçóes de categorias do transe não apenas integram uma espécie de diálogo do sujeito consigo mesmo, como também encarnam relaçôes sociais. Sempre manifestam a possibilidade de uma alteridade íntima, que se desdobra em alteridade social ( $\mathrm{p}$. 167-168).

Porém, cabe definir o que se implica pela dimensão enunciativa da possessão. Quem efetivamente enuncia produzindo efeitos discerníveis tanto no nível simbólico-estrutural do sistema quanto no de uma semântica do vivido que organiza e integra aspectos existenciais e subjetivos do agente religioso? Certamente não o médium resumido à sua individualidade, consciência redutível a uma dimensão psíquica objetiva, mas algo de si além da sua autorrepresentaçáo que tem como marca indelével a insistência em fazer-se movimento, forçando trilhas de sentido possíveis através dos significantes disponibilizados pelo Outro. Mais especificamente, quem enuncia são os espíritos, pensados não enquanto entidades proposicionalmente conceptualizáveis — afinal, não se pretende dizer o que os espíritos em última instância são, procedimento que desvirtuaria a proposta em algum tipo de teologia ou metafísica - , mas enquanto realizações subjetivas de algum aspecto do ser irredutível à consciência. Na umbanda, os espíritos realizam dimensôes do Espírito

como "letras" (na acepção psicanalítica lacaniana) em função de agência, "inscritas" corporalmente; e portanto operam como significantes (representantes do sujeito perante outros significantes) plasticamente antropomorfizados para mediarem "corporalmente" uma interlocuçáo com a totalidade do idioma. $\mathrm{Na}$ qualidade de agente, suposto sujeito, o espírito é inobjetivável, podendo configurar-se na posição de "eu", "tu", "ele"; e ao mesmo tempo supor-se "vento", "folha”, "cobra”... (Bairrão, 2011b, p. 168).

Em outros termos, na possessáo, quem enuncia é o Outro enquanto agente que se identifica com o enunciado e pronuncia-se "eu” (Bairrão, 2008a), função de alteridade que interpela desde o íntimo do ser, desde o abismo que constitui o sujeito enquanto dividido e marcado pela falta (Lacan, 1966/1998), que diz, espelha e implica transferencialmente e para além da consciência. O Outro se apresenta e enuncia como sujeito do inconsciente, entendido lacanianamente não enquanto espaço mental depositário de representaçóes psíquicas, mas em termos semióticos, 
como lugar de enunciação de natureza desconhecida estabelecido fora dos limites da consciência, onde o sujeito se percebe e recebe pelos meios da mediação simbólica (Bairrão, 2006).

Tais consideraçôes permitem retirar da análise da possessão a noção de que seus elementos simbólicos estão como que localizados em uma dimensão de exterioridade, espécie de revestimento, em relaçáo a supostos processos internos conformativos do psiquismo. Na verdade, lacanianamente entendida, o que se passa na possessão é da ordem de um "atravessamento" em que não faz sentido a dicotomia interior/exterior, em que a construção da realidade não redutível ao linguístico, uma vez que o corpo e o gestual já possuem uma dimensão simbólica - e do que quer que seja da ordem do indivíduo não é senão uma produção de efeito das (e nas) combinatórias possíveis entre a presentificação de um real incognoscível e imperativo e o universo cultural (significante) disponível, assimilado intersubjetivamente através dos encontros estabelecidos com outros agentes (sejam eles espíritos, deuses, ou pessoas concretas) socialmente acessíveis. De fato, não há sujeito sem o Outro, e sem sujeito, sem uma existência encarnada no significante, o Outro se resumiria a uma espécie de sistema computacional, conjunto "morto" de regras lógicas desabitado pela verdade, destituído de ser (Lacan, 1998/1999).

\section{Consideraçóes Finais}

Ao conceber-se enquanto um aparato comunicativo e expressivo capaz de instrumentar seus praticantes a dar voz e lugar a sentidos e saberes individuais ou coletivos que se enunciam outros além da consciência, o fenômeno da possessão necessita de uma abordagem teórico-metodológica apta a capturar aquilo que a constitui em sua essencialidade: a existência de um sistema simbólico em movimento, espaço de significância e alteridade no qual se articulam e atualizam realidades possíveis e posiçóes legítimas desde onde o ser vivente pode reconhecer a si mesmo em toda a sua multiplicidade enquanto sujeito agente no mundo e na história. Para tanto, a psicanálise lacaniana apresenta-se como alternativa útil e relevante.

Não apenas permite ultrapassar dicotomias antigas e caras ao pensamento ocidental, tais como interioridade/exterioridade e biopsíquico/sociocultural, como também, por seu intermédio, as relaçóes entre médiuns, consulentes e os seus interlocutores espiri- tuais podem ser consideradas em suas particularidades, dando ouvidos não apenas às diversas posiçóes de estar-se sujeito, como também, e principalmente, a outras vozes (históricas, sociais, políticas, etc.) e temáticas (saúde, étnicas, de gênero etc.) que as atravessam, sem que obrigatoriamente o pesquisador tenha de tomar partido e decidir acerca de um significado geral do fenômeno (como a rápida revisão empreendida permitiu entrever, há muitos e diversos). Na realidade, por meio da possessão, podem ser ditas e dizem-se muitas coisas. A psicanálise lacaniana viabiliza que o pesquisador abdique da condição de quem atribui e sobrepóe significados à possessão, em prol da posição mais rigorosa de quem dá ouvidos às interpretaçóes e sentidos implícitos em cada manifestação do fenômeno.

\section{Referências}

Ambros, B. (2010). Vengeful spirits or loving spiritual companions? Changing views of animal spirits in contemporary Japan. Asian Ethnology, 69(1), 35-67.

Augras, M. (2008). O duplo e a metamorfose: a identidade mítica em comunidades nagô. Petrópolis: Vozes.

Bairrão, J. F. M. H. (2002). Subterrâneos da Submissão: sentidos do mal no imaginário umbandista. Memorandum: Memória e História em Psicologia, 2, 55-67.

Bairrão, J. F. M. H. (2003a). Caboclas de Aruanda: a construção narrativa do transe. Imaginário, 9, 285-322.

Bairrão, J. F. M. H. (2003b). Raízes da Jurema. Psicologia USP, 14(1), 157-184.

Bairrão, J. F. M. H. (2004). Sublimidade do mal e sublimação da crueldade: criança, sagrado e rua. Psicologia: Reflexâo e Crítica, 17(1), 61-73.

Bairrão, J. F. M. H. (2005). A Escuta participante como procedimento de pesquisa do sagrado enunciante. Estudos de Psicologia, 10(3), 441-446.

Bairrão, J. F. M. H. (2006). Psicologia cultural: tem a psicanálise alguma coisa a dizer sobre isso? Natureza Humana: Revista de Filosofia e Psicanálise, 8(1), 293-312.

Bairrão, J. F. M. H. (2007). Linguagem e corpo na umbanda. In: Arcuri, I. G., \& Lopez, M. A. (Orgs.), Temas em Psicologia da Religião (pp. 165184). São Paulo: Vetor.

Bairrão, J. F. M. H. (2008a). Possessão e autoria. In L. V. Tfouni, (Org.), Múltiplas faces da autoria: análise do discurso, psicanálise, literatura, modernidade e enunciação (pp. 101-120). Ijuí: Editora Unijuí. 
Bairrão, J. F. M. H. (2008b). Tulipa: subsídios para uma etnopsicanálise da possessão. Olhar (UFSCar), 10/11, 53-68.

Bairrão, J. F. M. H. (2011a). Adolescência em transe. In L. V. Tfouni, (Org.), Letramento, Escrita $e$ Leitura: questôes contemporâneas (pp. 83-100). Campinas: Mercado de Letras.

Bairrão, J. F. M. H. (2011b). Nominação e agência sem palavras: o audível não verbal num transe de possessão. In F. V., Bocca, F. Caropreso, \& R. T. Simanke, (Orgs.), O movimento de um pensamento: ensaios em homenagem a Luiz Roberto Monzani (pp. 155-172). Curitiba: CRV.

Birman, P. (1985). O que é umbanda. São Paulo: Brasiliense.

Boddy, J. (1988). Spirits and selves in northern Sudan: the cultural therapeutics of possession and trance. American Ethnologist, 15(1), 4-27.

Boddy, J. (1989). Wombs and Alien Spirits: Women, Men, and the Zar Cult in Northern Sudan. Wisconsin: The University of Wisconsin Press.

Bojuwoye, O. (2013). Integrating principles underlying ancestral spirits belief in counseling and psychotherapy. IFE Psychologia: an International Journal, 21(1), 74-89.

Bourguignon, E. (1973). Introduction: a framework for the comparative study of altered states of consciousness. In E. Bourguignon, (Org.), Religion, altered states of consciousness and social change (pp. 3-35). Columbus: Ohio State University Press.

Brac de la Perrière, B. (2007). To marry a man or a spirit? Women, the spirit possession cult, and domination in Burma. In P. Lawrence, \& $\mathrm{M}$. Skidmore, (Orgs.), Women and the contested state: religion, violence and agency in South and Southeast Asia (pp. 208-228). Notre Dame: University of Notre Dame.

Bragazzi, N. L., \& Del Puente, G. (2012). Panic attacks and possession by djinns: lessons from ethnopsychiatry. Psychology Research and Behavior Management, 5, 185-190.

Cardeña, E., Van Duijl, M., Weiner, L.A., \&Terhune, D. B. (2009). Possession/trance phenomena. In P. F. Dell, \& J. A. O'Neil, (Orgs.), Dissociation and the dissociative disorders: DSM-V and beyond (pp. 171-181). New York: Routledge/Taylor \& Francis Group.

Concone, M. H. V. B. (1987). Umbanda: uma religião brasileira. São Paulo: FFLCH-USP.
Concone, M. H. V. B. (2001). Caboclos e pretosvelhos da umbanda. In R. Prandi, (Org.), Encantaria Brasileira: o livro dos mestres, caboclos e encantados (pp. 281-303). Rio de Janeiro: Pallas.

Corin, E. (1998). Refiguring the person: the dynamics of affects and symbols in an African spirit possession cult. In In: Lambek, M., \& Strathern, A. (Orgs.), Bodies and persons: comparative perspectives from Africa and Melanesia (pp. 80-102). Cambridge: Cambridge University Press.

Crapanzano, V. (1977). mohammed and Dawia: possession in Morocco. In V. Crapanzano, \& V. Garrison, (Orgs.), Case studies in spirit possession (pp. 141-176). Canada: John Wiley e Sons.

Doi, T. (1973). The anatomy of dependence. New York: Kodansha International.

Favret-Saada, J. (2005). "Ser afetado" (P. Siqueira, trad.). Cadernos de Campo, 14(13), 155-161.

Goldman, M. (1984). A possessão e a construção ritual da pessoa no candomblé. Dissertação de Mestrado, Universidade Federal do Rio de Janeiro, Rio de Janeiro.

Guzder, J. (2007). Fourteen Djinns migrate across the ocean. In B. Drožðek, \& J. P. Wilson, (Orgs.), Voices of trauma: treating survivors across cultures (pp. 105-126). New York: Springer Science \& Business Media.

Hegeman, E. (2013). Ethnic syndromes as disguise for protest against colonialism: three ethnographic examples. Journal of Trauma \& Dissociation, 14(2), 138-146.

Hollan, D. (2000). Culture and dissociation in Toraja. Transcultural Psychiatry, 37(4), 545-559.

Johnson, P. C. (2011). An atlantic genealogy of "spirit possession". Comparative studies in society and history, 53(2), 393-425.

Kenyon, S. M. (1995). Zar as modernization in contemporary Sudan. Anthropological Quarterly, 68(2), 107-120.

Kramer, F. (1993). The red fez: art and spirit possession in Africa. London: Verso.

Lacan, J. (1998). Escritos. Rio de Janeiro: Jorge Zahar Editor. (Original publicado em 1966).

Lacan, J. (1999). O Seminário (Livro 5): As formaçôes do inconsciente. Rio de Janeiro: Jorge Zahar Editor. (Original publicado em 1998).

Lambek, M. (1980). Spirits and spouses: possession as a system of communication among the Malagasy speakers of Mayotte. American Ethnologist, 7(2), 318-331. 
Lambek, M. (1988). Spirit possession/spirit succession: aspects of social continuity among Malagasy speakers in Mayotte. American Ethnologist, 15(4), 710-731.

Leiris, M. (1996). La possession et ses aspects théâtraux chez les Éthiopiens de Gondar, précedée de la croyance aux génies zar en Éthiopie du Nord. In M., Leiris, Miroir de l'Afrique (pp. 949-1060). Paris: Gallimard. (Original publicado em 1958).

Levine, R. A. (2005). Levy's "tahitians": a model for ethnopsychology. Ethos, 33(4), 475-479.

Lewis, I. M. (1977). Extase religioso: um estudo antropológico da possessão por espírito e do xamanismo. São Paulo: Perspectiva.

Macedo, A. C., \& Bairrão, J. F. M. H. (2011). Estrela que vem do Norte: os baianos na umbanda de São Paulo. Paidéia (Ribeirão Preto), 21(49), 207-216.

Mageo, J. M. (1996). Spirit girls and marines: ethnopsychiatry as historical discourse in Samoa. American Ethnologist, 23(1), 61-82.

Masquelier, A. (2002). Confessions of a spirit medium in Niger. Ethos, 30(1), 49-76.

Nathan, T. (2005). The Djinns: a sophisticated conceptualization of pathologies and therapies. In R. Moodley, \& W. West, (Orgs.), Integrating traditional healing practices into counseling and psychotherapy (pp. 26-37). Thousand Oaks: Sage Publications Ltd.

Nelson, C. (1971). Self, spirit possession and world view: an illustration from Egypt. International Journal of Social Psychiatry, 17(3), 194-209.

Obeyesekere, G. (1981). Medusa's hair: an essay on personal symbols and religious experience. Chicago: The Chicago University Press.

Onchev, G. (2001). Heterogeneity of the possession experiences: a case study from Pemba. The European Journal of Psychiatry, 15(4), 217-224.

Pagliuso, L., \& Bairrão, J. F. M. H. (2010). Luz no caminho: corpo, gesto e ato na umbanda. AfroÁsia, 42, 195-225.

Rotta, R. R., \& Bairrão, J. F. M. H. (2010). Mulheres médiuns e caboclas espirituais. Arquivos Brasileiros de Psicologia, 62(2), 169-177.

Rotta, R. R., \& Bairrão, J. F. M. H. (2012). Sentido e alcance psicológicos de caboclos nas vivências umbandistas. Memorandum: Memória e História em Psicologia, 23, 120-132.

Snodgrass, J. G. (2002). Imitation is far more than the sincerest of flattery: the mimetic power of spirit possession in Rajasthan, India. Cultural Anthropology, 17(1), 32-64.
Stoller, P. (1995). Embodying colonial memories: spirit possession, power, and the Hauka in West Africa. New York: Routledge.

Swartz, L. (2011). Dissociation and spirit possession in non-western countries: notes towards a common research agenda. In V. Sinason, (Org.), Attachment, trauma and multiplicity: working with dissociative identity disorder (pp. 63-71). New York: Routledge.

Turner, V. (1988). The anthropology of performance. New York: PAJ Publications.

Van De Port, M. (2005). Circling around the really real: spirit possession ceremonies and the search for authenticity in Bahian candomblé. Ethos, 33(2), 149-179.

\section{Endereço para correspondência:}

José Francisco Miguel Henriques Bairrão

Faculdade de Filosofia, Ciências e Letras de Ribeirão Preto Departamento de Psicologia

Avenida Bandeirantes, 3.900

CEP 14040-901 - Ribeirão Preto/SP

E-mail: bairrao@ffclrp.usp.br

Recebido em 28/04/2013

Revisto em 11/09/2013

Aceito em 29/09/2013

Apoio financeiro: Coordenação de Aperfeiçoamento de Pessoal de Nível Superior (CAPES) e Fundação de Amparo à Pesquisa do Estado de Sáo Paulo (FAPESP). O artigo é uma retomada e reelaboraçáo de parte de uma dissertação de mestrado do primeiro autor, financiado com bolsa de mestrado CAPES. 